\#SPODF-17 Classificação e etiologia da mordida aberta - Revisão bibliográfica narrativa

Armandino Alves; Susana Silva; Rita Carvalho; Madalena Ribeiro

Universidade Católica Portuguesa

Introdução: No panorama atual da Ortodontia a mordida aberta apresenta-se como um tópico bastante estudado sendo o seu plano de tratamento muitas vezes alvo de controvérsia. Este é, cada vez mais, considerado como um desafio devido à forte tendência à recidiva. É assim de extrema importância uma correcta determinação da etiologia de modo a alcançar um tratamento estável. O objetivo deste trabalho será revisar determinados conceitos sobre a mordida aberta e auxiliar na execução de um diagnóstico preciso.

Métodos: Foram realizadas diferentes pesquisas nas plataformas online "Research Gate", "PubMed" e "Google Scholar" utilizando númeras palavras/expressões chave: "open bite", "open bite etiology" e "open bite classification". Após um processo de seleção com uma preferência por artigos publicados nos últimos 10 anos foram filtrados os resultados por "best match" e eleitos os artigos mais pertinentes para a execução da revisão sistemática em causa. Também foram consultados dois livros para auxiliar a pesquisa: "Clínica y Terapéutica" de Canut Brusola e "Ortodontia Contemporânea" de Proffit WR, Fields HW, Sarver DM.

Resultados: Há determinados fatores etiológicos que podem influenciar o aparecimento da mordida aberta: hereditariedade, patologia dentária, patologia óssea, desenvolvimento dentário, hábitos de sucção, deglutição atípica, hipotonicidade muscular e padrão morfogénico vertical. Mais recentemente tem sido debatido o tema da mordida aberta em relação a problemas respiratórios como é o caso da respiração anormal (mista ou oral) e o da apneia do sono apesar de não se ter estabelecido causalidade.

Conclusões: Em casos de mordida aberta, tanto verdadeira como falsa, a etiologia é frequentemente de origem multifatorial o que implicará um tratamento multidisciplinar.

Implicações clínicas: Segundo Proffit, apenas 5\% dos casos apresentam etiologia da mordida aberta diagnosticada, o que também pode ajudar a explicar a dificuldade acrescida no momento do tratamento, com o conhecimento dos mais importantes fatores etiológicos e manifestações clínicas será possível fazer um diagnóstico mais preciso e executar um plano de tratamento mais direcionado.

http://doi.org/10.24873/j.rpemd.2018.11.413

\section{\#SPODF-18 Corticotomias - Meios Facilitadores do Movimento Ortodôntico}

Inês Anselmo Assunção; Paulo Fernandes Retto; François Durand Pereira; Helder Nunes Costa; Pedro Mariano Pereira

Instituto Universitário Egas Moniz

Introdução: O tratamento ortôdontico facilitado pela cirurgia aparece em 1959 nos trabalhos de Heinrich Kole`s. Em 2001 os irmãos Wilcko descrevem um tratamento combinado entre a ortodontia e a periodontologia com a introdução de materiais de preenchimento ósseo sobre as osteotomias do osso cortical. O objetivo deste trabalho é fazer uma revisão da técnica e das suas indicações apresentando uma opção de tratamento nos casos limite ortodôntico-cirúrgicos.

Métodos: A terapia ortodôntica facilitada pela cirurgia é uma técnica ortodôntica recente, que apresenta, segundo os seus autores, diferentes abordagens clínicas no tratamento do adulto. Foi realizada uma revisão bibliográfica utilizando as palavras chave corticotomia, ortodontia facilitada pela periodontologia e ortodontia facilitada pela cirurgia.

Resultados: Existem variações da técnica de osteotomias utilizando cortes verticais, horizontais, piezoincisões ou perfurações da mucosa e utilizando diferentes tipos de materiais de preenchimento. A pré-existência de recessões gengivais no paciente adulto podem complicar o tratamento ortodôntico. Diversos autores preconizam uma correcção dos defeitos periodontais simultânea com as corticotomias facilitadoras do movimento ortodôntico. Na ortodontia combinada com cirurgia periodontal é feito um retalho com espessura total, incisões na tábua óssea externa por vestibular e/ou lingual dos sectores dentários a movimentar e enxertos ósseos na direcção do movimento ortodôntico. Pode ser uma alternativa nos casos limites ortodôntico-cirúrgicos. É uma opção a considerar nos casos de displasia transversal do maxilar e/ou apinhamento dentário severo.

Conclusões: Segundo as revisões sistemáticas avaliadas esta técnica é segura para os tecidos orais e reduz o tempo de tratamento. Segundo várias publicações apresenta vantagens como uma expansão dento-alveolar mais segura, a possibilidade de um maior movimento dentário, uma menor patologia periodontal, uma menor reabsorção radicular, menor perda de suporte alveolar e uma maior estabilidade do tratamento.

Implicações clínicas: Pretende-se com esta técnica aumentar os limites do tratamento ortodôntico. Para isso é fundamental realizar uma selecção adequada dos pacientes, definir os objetivos do tratamento, realizar um planeamento correcto e uma avaliação da quantidade de movimento dentário pretendido.

http://doi.org/10.24873/j.rpemd.2018.11.414

\#SPODF-19 Máscara facial em pacientes com fenda lábio-palatina - Revisão narrativa

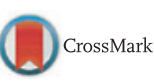

Adriana Armas Sobral; Inês Francisco; Ana Roseiro; Adriana Guimarães; Francisco Vale

Instituto de Ortodontia da Faculdade de Medicina da Universidade de Coimbra

Introdução: Pacientes com fenda lábio-palatina apresentam algumas características clínicas devido às cirurgias que são sujeitos para a correção da fenda, destacando-se a constrição do maxilar, bem como o colapso ântero-posterior, o que pode levar ao aparecimento da mordida cruzada. O objetivo deste póster é avaliar o efeito da máscara facial no perfil e na correção da mordida cruzada anterior em pacientes com fenda lábio-palatina. 
Métodos: Foi efetuada uma pesquisa nas bases de dados Pubmed e Cochrane Embase, obtendo-se artigos de 1989 a 2012, utilizando as seguintes palavras-chave: Cleft lip and palate; face mask; anterior crossbite; maxillary hipoplasia. Os critérios de inclusão utilizados foram publicações de 1989 a 2012 em inglês. Das quarenta publicações encontradas foram selecionadas dez.

Resultados: A literatura atual descreve frequentemente, uma resposta favorável da relação sagital quando o tratamento com máscara facial é iniciado precocemente. Apesar do efeito dento-facial ser diferente em fendas unilaterais (maior efeito esquelético) do que em fendas bilaterais (maior efeito dento-alveolar), as alterações do perfil foram semelhantes, indicando uma relação íntima entre os tecidos moles e as estruturas de tecido duro subjacentes.

Conclusão: A resposta esquelética ao tratamento com máscara facial parece indicar que uma harmonia sagital maxilo-mandibular é possível na maioria dos casos, havendo também uma melhoria na oclusão dentária e na aparência facial.

Implicações Clínicas: O uso de máscara facial no inicio da dentição mista é um tratamento ortopédico eficaz, na maioria dos casos, na correção da mordida cruzada anterior de pacientes com fenda lábio-palatina.

http://doi.org/10.24873/j.rpemd.2018.11.415 